\title{
A Novel Promazine Derivative Shows High in vitro and in vivo Antimicrobial Activity Against Staphylococcus aureus
}

\begin{abstract}
Troels Ronco ${ }^{1 \dagger}$, Nadia S. Jørgensen ${ }^{1 \dagger}$, Iben Holmer ${ }^{1}$, Sofie Kromann', Ehsan Sheikhsamani ${ }^{2}$, Anders Permin ${ }^{3}$, Søren W. Svenningsen ${ }^{4}$, Jørn B. Christensen ${ }^{4}$ and Rikke H. Olsen ${ }^{1 *}$

${ }^{1}$ Department of Veterinary and Animal Sciences, Faculty of Health and Medical Sciences, University of Copenhagen, Copenhagen, Denmark, ${ }^{2}$ Department of Animal Science, Faculty of Agriculture, Ferdowsi University, Mashhad, Iran, ${ }^{3}$ Unibrains, Virum, Denmark, ${ }^{4}$ Department of Chemistry, Faculty of Science, University of Copenhagen, Copenhagen, Denmark
\end{abstract}

The emergence of multidrug-resistant bacteria constitutes a significant public health issue worldwide. Consequently, there is an urgent clinical need for novel treatment solutions. It has been shown in vitro that phenothiazines can act as adjuvants to antibiotics whereby the minimum inhibitory concentration (MIC) of the antibiotic is decreased. However, phenothiazines do not perform well in vivo, most likely because they can permeate the blood-brain (BBB) barrier and cause severe side-effects to the central nervous system. Therefore, the aim of this study was to synthesize a promazine derivate that would not cross the BBB but retain its properties as antimicrobial helper compound. Surprisingly, in vitro studies showed that the novel compound, JBC 1847 exhibited highly increased antimicrobial activity against eight Gram-positive pathogens (MIC, 0.5-2 mg/L), whereas a disc diffusion assay indicated that the properties as an adjuvant were lost. JBC 1847 showed significant $(P<0.0001)$ activity against a Staphylococcus aureus strain compared with the vehicle, in an in vivo wound infection model. However, both in vitro and in silico analyses showed that JBC 1847 possesses strong affinity for human plasma proteins and an Ames test showed that generally, it is a non-mutagenic compound. Finally, in silico predictions suggested that the compound was not prone to pass the BBB and had a suitable permeability to the skin. In conclusion, JBC 1847 is therefore suggested to hold potential as a novel topical agent for the clinical treatment of $S$. aureus skin and soft tissue infections, but pharmacokinetics and pharmacodynamics need to be further investigated.

Keywords: phenothiazine derivative, novel antimicrobial compound, topical agent, Staphylococcus aureus, skin infections

\section{INTRODUCTION}

Across the globe, emerging multidrug-resistant human and veterinary bacterial pathogens constitute a considerable public health issue and cost many lives every year. Among these pathogens, methicillin-resistant Staphylococcus aureus (MRSA) and thirdgeneration cephalosporin-resistant Escherichia coli are some of the most problematic (Coates et al., 2011; Cassini et al., 2019). Therefore, there is an urgent clinical need 
for novel treatment solutions but at the same time the number of novel antibiotics introduced to the market has decreased considerably the last decades (Ventola, 2015; Singer et al., 2019). As a result, alternatives to antibiotics have extensively been investigated and previous studies suggest that phenothiazines can be applied as adjuvants to specific antibiotics, thereby increasing the bacterial susceptibility to the antimicrobial agent (Kristiansen et al., 2003, 2006). Phenothiazines constitute a group of neuroactive compounds that can act as a dopamine antagonists and have originally been used as antipsychotics (Snyder et al., 1974). In general, phenothiazines possess low antimicrobial activity compared with commercial antimicrobials and, e.g., the minimum inhibitory concentration (MIC) of promazine against a MRSA strain, has been reported to be $128 \mathrm{mg} / \mathrm{L}$ (Nehme et al., 2018). However, when used as helper compounds in combination with specific antibiotics, e.g., beta-lactams, they can cause a synergistic effect by decreasing the MIC of the antibiotic, probably by inhibiting efflux pumps (Kristiansen et al., 2007, 2010). However, it appears to be difficult to apply phenothiazines as an antimicrobial helper compound in clinical practice. The concentration of phenothiazines must be relatively high to obtain the synergistic effects, and studies have revealed that these compounds did not perform well as helper compounds when tested in vivo. In some cases, the administrated dose needed to be reduced considerably due to severe side-effects observed in the phenothiazine-treated animals (Stenger et al., 2015, 2017). Since phenothiazines possess lipophilic properties, they can easily cross the blood-brain barrier (BBB) and cause effects on the central nervous systems (CNS) (Seelig et al., 1994). Therefore, we have hypothesized that the toxic side-effects caused by phenothiazines during in vivo studies are partly due to effects on the brain. The main purpose of this study was to chemically modify promazine, a compound belonging to the phenothiazine group, so that it would not permeate the $\mathrm{BBB}$ but retain its properties as an antimicrobial helper compound. A further purpose was to assess the properties and safety of the novel derivate using in vitro, in vivo, and in silico approaches.

\section{MATERIALS AND METHODS}

\section{Synthesis of JBC 1847}

A mixture of promazine (1.0 g; $3.3 \mathrm{mmol}), 3$,7-dimethyloct-6-en1-yl 4-methylbenzenesulfonate (1.2 g; $3.8 \mathrm{mmol}$ ) (synthesized by the procedure by Zarbin et al., 2000) in acetonitrile $(25 \mathrm{ml})$ was heated to $+40^{\circ} \mathrm{C}$ and kept at $+40^{\circ} \mathrm{C}$ for 5 days. The acetonitrile was removed in vacuo, and diethyl ether $(50 \mathrm{ml})$ was added with stirring to the residue making the product crystallize. The product was isolated by filtration and dried in vacuum to give JBC 1847 a 58\% yield (1.2 g). All the chemicals were obtained from Sigma-Aldrich and were used as received.

\section{Investigating the Antimicrobial Activity in vitro}

Based on Clinical and Laboratory Standards Institute's (CLSI's) guidelines the MIC and the minimum bactericidal concentration (MBC) values for JBC 1847 were determined for 11 human and veterinary clinical isolates (Table 1). Initially, the broth microdilution method was used, and the strains were generally grown aerobically overnight $(\mathrm{ON})$ at $37^{\circ} \mathrm{C}$ on Mueller-Hinton agar (MHA) (Sigma, Copenhagen, Denmark) supplemented with $5 \%$ bovine blood. However, Cutibacterium acnes was grown anaerobically at $37^{\circ} \mathrm{C}$ for approximately $72 \mathrm{~h}$ on tryptone soya agar (TSA) (tryptic soy agar, Oxoid, Roskilde, Denmark). Colonies were suspended in $0.9 \% \mathrm{NaCl}$ to an optical density of 0.5 McFarland standard using a Sensititre ${ }^{\mathrm{TM}}$ nephelometer (Thermo Scientific $^{\text {TM }}$, Roskilde, Denmark). Subsequently, the suspensions were diluted 100-fold in Mueller-Hinton broth (MHB) and 100 $\mu \mathrm{l}$ of the dilution was transferred to the wells of a sterile 96well plate containing $100 \mu \mathrm{l} \mathrm{MHB}$ with JBC 1847 resulting in concentrations ranging from 0.02 to $256 \mathrm{mg} / \mathrm{L}$ and a final volume of $200 \mu \mathrm{l}$. The inoculum of all wells including positive controls containing only $\mathrm{MHB}$, was therefore $1.5 \times 10^{5}$ colony forming units (CFU) whereas the negative controls contained only MHB. All 96-well plates were grown aerobically as previously described except $C$. acnes that was incubated anaerobically as previously described in brain heart infusion (BHI; Sigma, Copenhagen, Denmark) media with 1\% L-cysteine (Blaskovich et al., 2019). The concentration in wells with no visible bacterial growth was defined as the MIC. The MBC for all isolates was determined by culturing $10 \mu \mathrm{l}$ from the MIC wells and all other wells with no visible growth, on TSA aerobically as previously described. The MBC for $C$. acnes was determined on $\mathrm{BHI}$ agar with $1 \% \mathrm{~L}$ cystein incubated as previously described. $\mathrm{MBC}$ was defined as the lowest concentration of JBC 1847 that reduced the CFU of the original inoculum $\left(1.5 \times 10^{5} \mathrm{CFU}\right)$ by $\geq 99.9 \%$. Both MIC and $\mathrm{MBC}$ values were determined in biological duplicates except for C. acnes and Staphylococcus epidermidis where only technical duplicates were used.

In addition, whether serum proteins affected the activity of JBC 1847 against three S. aureus strains (USA300 JE2, ATCC BAA-1556 and CC398 in house strain) was investigated. Broth microdilution assays analog to previously described, with a $20 \%$ human serum (Sigma-Aldrich, Brøndby, Denmark) concentration were carried for three $S$. aureus strains (Table 1). $\mathrm{MIC}$ and $\mathrm{MBC}$ values were determined as previously described.

To determine if eight different antibiotics from six classes had an impact on the activity of JBC 1847, agar dilution, and disc diffusion assays based on CLSI's guidelines were performed with two $S$. aureus strains (USA300 JE2 and ATCC-BAA). Initially, MHA plates with JBC 1847 concentrations ranging from 0.5 to $8 \mathrm{mg} / \mathrm{L}$ were made and bacterial inoculum was prepared as previously described, was added to each plate. After incubation as previously described, the MIC was determined as the lowest concentration that resulted in inhibition of bacterial growth. The MIC values for the two $S$. aureus strains were both determined to $4 \mathrm{mg} / \mathrm{L}$ and therefore, TSA plates with a JBC 1847 concentration of $2 \mathrm{mg} / \mathrm{L}$ were prepared to ensure the strains were able to grow. One dish of each type of antibiotic was added to a single TSA plate with JBC 1847 and a control plate containing only TSA and inoculated as previously described. Two plates containing only $2 \mathrm{mg} / \mathrm{L}$ JBC 1847 and bacterial inoculum for each strain served as a positive control. After incubation, clearing zones were measured and compared between control and JBC 1847 plates. 
TABLE 1 | Broth microdilution results for JBC 1847.

\begin{tabular}{|c|c|c|c|c|}
\hline Species & Strain & Origin & MIC (mg/L) & $M B C(\mathrm{mg} / \mathrm{L})$ \\
\hline Staphylococcus aureus & USA300 JE2 & Human clinical isolate & 0.5 & 0.5 \\
\hline S. aureus & ATCC BAA-1556 & Human clinical isolate & 0.5 & 0.5 \\
\hline S. aureus & CC398 (in house strain) & Veterinary clinical isolate & 0.5 & 0.5 \\
\hline Staphylococcus epidermidis & $\mathrm{RP62a}$ & Human clinical isolate & 0.5 & ND \\
\hline S. epidermidis & 105 (in house strain) & Human clinical isolate & 0.5 & ND \\
\hline Cutibacterium acnes & P10140156 (in house strain) & Human clinical isolate & $0.5-1$ & $0.5-1$ \\
\hline Enterococcus faecalis & JEO72G7B & Veterinary clinical isolate & 1 & 1 \\
\hline Enterococcus faecium & ATCC 700221 & Human clinical isolate & 2 & $2-4$ \\
\hline Proteus vulgaris & JEO1 & Veterinary clinical isolate & 32 & 32 \\
\hline Escherichia coli & E2 (in house strain) & Human clinical isolate & 8 & 8 \\
\hline E. coli & APEC O2 (in house strain) & Veterinary clinical isolate & 16 & 16 \\
\hline
\end{tabular}

The table shows minimal inhibitory concentrations (MIC) and minimal bacterial concentrations (MBC) of JBC1847 determined for 11 human or veterinary clinical isolates. ND, not determined.

\section{Induced JBC 1847 Tolerance}

To study if resistance toward JBC 1847 is easily developed, $S$. aureus USA300 was continuously exposed to increasing concentrations of JBC 1847 during a period of 23 days in an assay inspired by a previous study (Wassmann et al., 2018). This assay was carried out in technical duplicates as described for the MIC assay, except that concentrations of JBC 1847 varied. Initially, USA300 colonies were used to prepare a McFarland solution with an optical density of 0.5 . The McFarland solution was diluted in MHB and used as inoculum in wells with a final concentration of $0.25,0.5$, and $0.75 \mathrm{mg} / \mathrm{L} \mathrm{JBC} 1847$ and a final volume of $200 \mu$ l. The 96 -well plate was grown aerobically ON at $37^{\circ} \mathrm{C}$, and the next day, the highest concentration where growth was observed was in the $0.5 \mathrm{mg} / \mathrm{L}$ well. Therefore, bacterial culture from this well was diluted 1:100 and used as inoculum for wells with a final concentration of $0.5,0.75$, and $1.0 \mathrm{mg} / \mathrm{L}$ JBC 1847. This cycle was repeated during a period of 23 days and if no increase in resistance was observed the strain was grown in the same concentrations as the previous day. However, in the last 8 days, the assay was performed in $20 \mathrm{ml}$ test tubes in a volume of $2 \mathrm{ml}$. As for the 96 wells, pure MHB served as negative control, whereas inoculum in pure MHB served as positive control. Approximately every 2 nd day during the 23 days period, $10 \mathrm{ml}$ of the daily inoculum was transferred to MH blood agar plates and cultivated as previously described to ensure no contamination was present. Simultaneously, an identical assay was performed using fusidic acid natrium salt (Sigma). Here, the starter concentration was $0.03 \mathrm{mg} / \mathrm{L}$ corresponding to the MIC value for USA300, determined using the broth microdilution method as previously described. The daily concentration was first increased by $0.02 \mathrm{mg} / \mathrm{L}$, but later on, during the period of 23 days, the concentrations were increased by values ranging from 0.250 to $1 \mathrm{mg} / \mathrm{L}$.

\section{Growth and Viability Assays}

Growth and viability assays were performed according to a previously published method (Thorsing et al., 2013), with some modifications. In general, the assay was conducted over a 24 $\mathrm{h}$ period in a $37^{\circ} \mathrm{C}$ heating bath with shaking, using S. aureus USA300 JE2 as test strain. The strain was exposed to sub- and
supra-MIC of JBC 1847, and for each concentration, samples were collected at eight different timepoints during the $24 \mathrm{~h}$ period. To determine the MIC for the test strain, a single colony incubated on MHA with blood at $37^{\circ} \mathrm{C}$ for $20-22 \mathrm{~h}$ was inoculated into $\mathrm{BHI}$ broth and further incubated at $37^{\circ} \mathrm{C}$ with shaking for 20-22 h. The culture was diluted 1:100 in BHI broth and grown to early exponential phase $\left(\mathrm{OD}_{600} 0.20\right)$. The culture was divided into four flasks each with a volume of $100 \mathrm{ml} \mathrm{BHI}$ broth and a JBC 1847 concentration of 2, 4, 8, or $16 \mathrm{mg} / \mathrm{L}$. The flasks were grown in $37^{\circ} \mathrm{C}$ with shaking for $20-22 \mathrm{~h}$, and the MIC was visually determined to $4 \mathrm{mg} / \mathrm{L}$. To test the viability of USA300 JE2 when exposed to JBC 1847, an ON culture was prepared and diluted as previously described and $4 \mathrm{ml}$ was subsequently added to $400 \mathrm{ml} \mathrm{BHI}$ broth. This culture was grown to $\mathrm{OD}_{600} 0.20$ where sample zero was collected. Subsequently, the culture was divided into four flasks whereof one served as untreated control and the remaining three had a concentration of 2,4 , and $16 \mathrm{mg} / \mathrm{L}$. Flasks were incubated at $37^{\circ} \mathrm{C}$ with shaking, and samples were collected when adding JBC 1847 and 1, 2, 3, 4, 5, 8, and $24 \mathrm{~h}$ after. $100 \mu \mathrm{l}$ samples were serially diluted, spread on MHA plates, and incubated at $37^{\circ} \mathrm{C}$ for $20-24 \mathrm{~h}$ followed by successive counting.

\section{Transmission Electron Microscopy}

To elucidate the interaction between JBC 1847 and MRSA USA300, transmission electron microscopy (TEM) was carried out. Bacterial cultures were inoculated in $10 \mathrm{ml} \mathrm{MHB}$ and cultivated at $37^{\circ} \mathrm{C}$ for $5 \mathrm{~h}$, with shaking, until mid-exponential growth phase $\left(\mathrm{OD}_{550}\right.$ 5.5). Once mid-exponential phase was reached, the cells were treated according to the sub- and supraMIC $(0.5 \times$ MIC, MIC, $2 \times$ MIC, and $4 \times$ MIC $)$ of JBC1847 at $37^{\circ} \mathrm{C}$ for $1 \mathrm{~h}$. An untreated control was also prepared. The five samples were placed on ice until being prepared for TEM. This included a fixation step in $2 \%$ glutaraldehyde in $0.15 \mathrm{M}$ sodium phosphate buffer ( $\mathrm{pH}$ 7.2). Subsequently, the fixed cells were washed three times and postfixed with $0.2 \% \mathrm{OsO}_{4}$ (osmium tetroxide) in $\mathrm{H}_{2} \mathrm{O} / 0.15 \mathrm{M}$ sodium phosphate buffer ( $\mathrm{pH}$ 7.2) for $1 \mathrm{~h}$. The samples were then dehydrated with graded acetone, and then embedded in epoxy resin. Ultrathin sections of the samples were prepared using Formvar-coated copper grids, which were stained using 3\% uranyl acetate. The samples were placed 
in a Philips CM 100 Transmission EM (Philips, Eindhoven, Netherlands) and exposed to $120 \mathrm{keV}$ electron energy.

\section{Assessment of the Efficacy of JBC 1847 in vivo}

To study the effect of topical treatment with JBC 1847 against MRSA strain 43484, a mouse skin infection model was established. Initially, female mice (18-22 g) were orally treated with $45 \mu \mathrm{l}$ nurofen $(20 \mathrm{mg}$ ibuprofen/ml) and anaesthetized with $0.15 \mathrm{ml}$ s.c. of Zoletil mix. The fur was removed from an area of $6 \mathrm{~cm}^{2}$ and a part of epidermis was subsequently scraped off to obtain a $1 \mathrm{~cm}^{2}$ superficial skin lesion. The mice were inoculated with $10 \mu \mathrm{l}$ of a saline solution containing approximately $10^{7} \mathrm{CFU}$. The day after inoculation, topical treatment with $50 \mu \mathrm{l}$ test compound was initiated and performed twice daily for a 3-day period. Fucidic acid was included as a positive control, and vehicle treatment was included as a negative control. Through the entire study, the behavior and clinical signs of the mice were carefully observed. Mice were killed the day after last treatment, and skin biopsies from the wounded area were collected. The skin samples were homogenized using a Dispomixer and serially diluted in saline/Triton X. To determine the bacterial concentration, $20 \mu \mathrm{l}$ spots were transferred to MRSA Brilliance agar plates (Oxoid, Thermo Scientific, Roskilde, Denmark) and incubated $20-48 \mathrm{~h}$ at $35^{\circ} \mathrm{C}$.

\section{Pharmacological Predictions in silico}

Online tools and software packages were applied to predict the pharmacodynamics and pharmacokinetics of JBC 1847. The following three tools were used: VEGA-QSAR, v1.1.5 (Benfenati et al., 2013), SwissADME (Daina et al., 2017), and PreADMET (PreADMET, 2019) together with the two SMILES formulas.

JBC 1847: $(\mathrm{CC}(\mathrm{CCC}=\mathrm{C}(\mathrm{C}) \mathrm{C}) \mathrm{CC}[\mathrm{N}+](\mathrm{C})(\mathrm{C}) \mathrm{CCCN} 1 \mathrm{C} 2=\mathrm{C}$ ( $\mathrm{SC} 3=\mathrm{C} 1 \mathrm{C}=\mathrm{CC}=\mathrm{C} 3) \mathrm{C}=\mathrm{CC}=\mathrm{C} 2)$.

Promazine: $(\mathrm{CN}(\mathrm{C}) \mathrm{CCCN} 1 \mathrm{C} 2=\mathrm{CC}=\mathrm{CC}=\mathrm{C} 2 \mathrm{SC} 3=\mathrm{CC}=\mathrm{C}$ $\mathrm{C}=\mathrm{C} 31)$.

The formulas were converted to MOLfiles using the online server Cheminfo.org, 2019.

\section{Ames Test}

To investigate if JBC 1847 exhibited mutagenic properties, Ames mutagenicity test was performed. In this reverse mutation assay, five bacterial tester strains recommended by The Organization for Economic Cooperation and Development (OECD), were exposed to JBC 1847 in presence and absence of a metabolic activation system (S9) obtained from rat liver extract (Maron and Ames, 1983; Levy et al., 2019). The characteristics of the four Salmonella typhimurium mutants (TA98, TA100, TA1535, TA1537) and a single Escherichia coli mutant [wp2 (pKM101)] have been described by Mortelmans and Zeiger (2000) and Levy et al. (2019). Prior to testing, the genotypes of all strains were confirmed as previously described (Mortelmans and Zeiger, 2000), and JBC 1847 was tested in various concentrations $(1.5,4,10,25,64,160$, 400 , and 1,000 $\mu \mathrm{g} /$ well) whereas DMSO served as negative control. As positive controls, five mutagenic compounds were applied in various concentrations (Supplementary Material). The Ames test was performed as described in Supplementary Material where acceptance criteria for the test results can also be found. To evaluate the test results, the mutagenicity ratio (MR) was calculated and interpreted as in previous studies (Pah and Lakhani, 2012; Wang et al., 2018). The MR was calculated as MR $=x / x_{\mathrm{n}}$. Here, $x$ was the number of reverse mutated colonies exposed to JCB 1847 whereas $x_{\mathrm{n}}$ was the number of reverse mutated colonies in the negative controls. A MR of $\geq 2$ was interpreted as positive regarding mutagenicity.

\section{Statistical Analyses}

Data were statically analyzed and visualized using RStudio v3.6.3 (R Core Team, 2020) and Microsoft excel. In general, the values reflecting the bacterial concentration $(\mathrm{CFU} / \mathrm{ml})$ were transformed into a logarithmic scale. In the growth and viability assay, the mean numbers of the bacterial concentrations from the triplicates were plotted against time and standard deviations shown as error bars. To investigate differences in bacterial concentration between treatment groups in the in vivo assay, multiple group comparisons were performed using ANOVA and $P<0.05$ considered significant. The data was visualized in a standard box plot.

\section{RESULTS}

\section{Synthesis of JBC 1847}

As mentioned in the "INTRODUCTION," phenothiazines can easily cross the $\mathrm{BBB}$ and possibly cause negative effects on the CNS (Seelig et al., 1994). We hypothesized that adding an alkyl group to the tertiary amine of promazine to form a quaternary ammonium ion would prevent a compound from penetrating the BBB. The choice of a citronnelyl group (systematic name: 3,7-dimethyloct-6-en-1yl) as a tail, was based on an idea that the structure of the tail (which is a monoterpene) might be recognized as a potential carbon and energy source (Marmulla and Harder, 2014) and may help the rest of the molecule to enter the bacteria.

The yield of JBC 1847 was $1.2 \mathrm{~g}(58 \%)$. HRMS (ESI): 423.2879 $\left(\mathrm{M}^{+}\right.$, calcd. for $\mathrm{C}_{27} \mathrm{H}_{39} \mathrm{~N}_{2} \mathrm{~S}^{+}$: 423.28). ${ }^{1} \mathrm{H}-\mathrm{NMR}(500 \mathrm{MHz}$, $\left.\mathrm{CDCl}_{3}\right) \delta: 7.77(\mathrm{~d}, 2 \mathrm{H}, J=10 \mathrm{~Hz}), 7.22-7.17(\mathrm{~m}, 4 \mathrm{H}), 7.14(\mathrm{~d}$, $2 \mathrm{H}, J=10 \mathrm{~Hz}), 7.00-6.96(\mathrm{~m}, 2 \mathrm{H}), 6.92-6.90(\mathrm{~m}, 2 \mathrm{H}), 5.04(\mathrm{~s}$, $1 \mathrm{H}), 4.09-4.03(\mathrm{~m}, 2 \mathrm{H}), 3.64-3.56(\mathrm{~m}, 2 \mathrm{H}), 3.20-3.06(\mathrm{~m}, 8 \mathrm{H})$, $2.37(\mathrm{~s}, 3 \mathrm{H}), 2.28-2.19(\mathrm{~m}, 2 \mathrm{H}), 1.70(\mathrm{~s}, 3 \mathrm{H}), 1.60(\mathrm{~s}, 3 \mathrm{H}), 1.46-$ $1.10(\mathrm{~m}, 2 \mathrm{H}), 1.30-1.10(\mathrm{~m}, 3 \mathrm{H}), 1.00-0.91(\mathrm{~m}, 2 \mathrm{H})$, and 0.69 $(\mathrm{d}, 3 \mathrm{H}, J=10 \mathrm{~Hz}) .{ }^{13} \mathrm{C}-\mathrm{NMR}\left(126 \mathrm{MHz}, \mathrm{CDCl}_{3}\right) \delta: 144.65$, $143.97,139.08,131.76,129.80,128.59,127.81,126.02,125.91$, $123.89,123.27,116.30,62.52,60.87,51.56,43.76,36.71,30.22$, 28.96, 25.74, 25.22, 21.31, 20.07, 18.76, and 17.75.

Elemental analysis: calcd. for $\mathrm{C}_{34} \mathrm{H}_{46} \mathrm{~N}_{2} \mathrm{O}_{3} \mathrm{~S}_{2}$ : C, $68.65 \% ; \mathrm{H}$, $7.79 \%$; and N, $4.71 \%$. Found: C, $68.37 \%$; H, $7.56 \%$; and N, $4.67 \%$.

The structure of JBC 1847 and its anion is shown in Figure 1. 


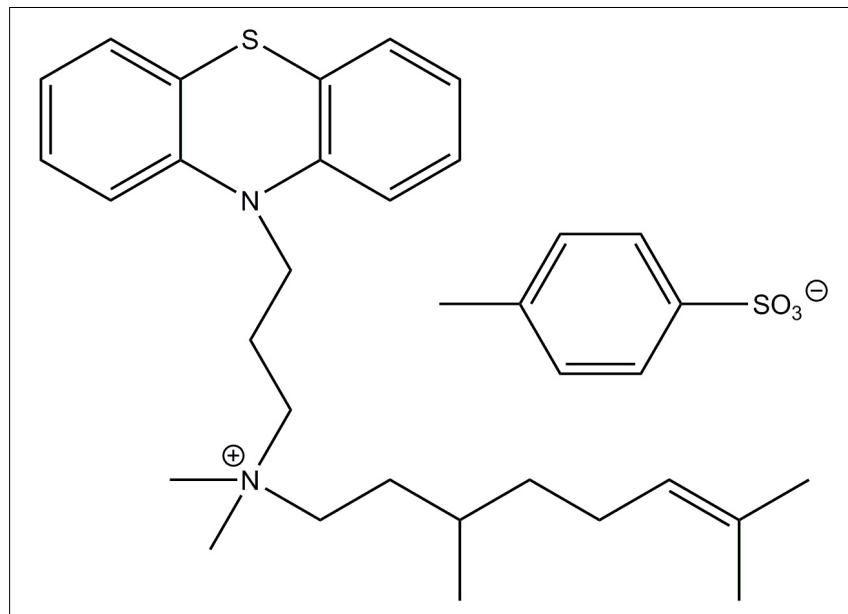

FIGURE 1 | The structure of JBC 1847 and its anion.

\section{Antimicrobial Activity in vitro}

JBC 1847 was tested for activity against eight Gram-positive and three Gram-negative pathogenic bacteria using the broth microdilution method. The MIC values ranged from 0.5 to $2 \mathrm{mg} / \mathrm{L}$ for Gram-positive and from 8 to $32 \mathrm{mg} / \mathrm{L}$ for Gramnegative bacteria (Table 1). In all cases except for E. faecium ATCC 700221, the MIC values corresponded to the MBC values. When JBC 1847 was tested against three clinical MRSA isolates (USA300 JE2, ATCC BAA-1556 and CC398 in house strain) in a broth microdilution assay with a $20 \%$ human serum concentration, the MIC and MBC value were found to be $64 \mathrm{mg} / \mathrm{L}$ for all three strains. This is a 128 -fold increase (from 0.5 to $64 \mathrm{mg} / \mathrm{L}$ ) in both the MIC and the MBC values for all three strains, compared with the assay without human serum (Table 1).

In addition, whether JBC 1847 had an impact on the activity of eight antimicrobial compounds belonging to six different classes against two clinical MRSA strains was investigated. No remarkable synergistic or antagonistic effects were observed, and for both test strains, the change in diameter of the clearing zone ranged from -1.7 to $12 \%$ between control and test plates (Tables 2, 3). However, when strain ATCC-BAA 1556 was tested in the presence of tetracycline, a $25 \%$ change in diameter between control and test plates was observed (Table 2).

\section{Induced JBC 1847 Tolerance}

The results showed that the increase in MIC for fusidic acid (233-fold) was remarkably high compared with JBC 1847 (7fold) when tested against MRSA USA300 during the 23 days (Table 4). In addition, the highest MIC (3.5 mg/L) for JBC 1847 was reached at day 4 , and hereafter, these MIC values ranged from 1 to $2.5 \mathrm{mg} / \mathrm{L}$. In contrast, the MIC value for fusidic acid was continuously increasing and peaked with $7 \mathrm{mg} / \mathrm{L}$ on the final day (Table 4).

\section{Growth and Viability Assays}

To study the correlation between the concentration of JBC 1847 and viability of $S$. aureus USA300 JE2 an assay lasting for $24 \mathrm{~h}$
TABLE 2 | JBC 1847 activity against Staphylococcus aureus ATCC-BAA 1556 in presence of eight antibiotics.

\begin{tabular}{lccc}
\hline Antibiotic $(\boldsymbol{\mu} \mathbf{g})$ & $\begin{array}{c}\mathbf{2} \mathbf{~ \mathbf { g }} \mathbf{\mathbf { L }} \mathbf{~ J B C} \\
\mathbf{1 8 4 7}(\mathbf{m m})\end{array}$ & $\begin{array}{c}\text { Control plates } \\
\mathbf{( m \mathbf { m } )}\end{array}$ & Change (\%) \\
\hline Ampicillin (10) & $30-32$ & 30 & 3.3 \\
Oxacillin (1) & 20 & 18 & 11.1 \\
Erythromycin (15) & 17 & 17 & 0 \\
Enrofloxacin (5) & 18 & 17 & 5.9 \\
Vancomycin (30) & 12 & 12 & 0 \\
Tetracycline (30) & 10 & 8 & 25 \\
Gentamicin (10) & 22 & 21 & 4.8 \\
Ciprofloxacin (5) & 12 & 10 & 12 \\
\hline
\end{tabular}

The table shows clearing zones $(\mathrm{mm})$ observed when eight antibiotics were tested against S. aureus ATCC-BAA 1556 in absence (control) and presence of JBC 1847 (2 $\mathrm{mg} / \mathrm{L})$. The change (\%) indicates the difference in clearing zones.

TABLE 3 | JBC 1847 activity against Staphylococcus aureus USA300 in presence of eight antibiotics.

\begin{tabular}{lccc}
\hline Antibiotic $(\boldsymbol{\mu} \mathbf{g})$ & $\begin{array}{r}\mathbf{2} \mathbf{~ \mathbf { g }} \mathbf{\text { L JBC}} \\
\mathbf{1 8 4 7}(\mathbf{m m})\end{array}$ & $\begin{array}{c}\text { Control plates } \\
\mathbf{( m m})\end{array}$ & Change (\%) \\
\hline Ampicillin (10) & $31-33$ & $28-30$ & 10.3 \\
Oxacillin (1) & $18-20$ & $18-20$ & 0 \\
Erythromycin (15) & $27-30$ & $28-30$ & -1.7 \\
Enrofloxacin (5) & 18 & 17 & 5.9 \\
Vancomycin (30) & 10 & 10 & 0 \\
Tetracycline (30) & 27 & 27 & 0 \\
Gentamicin (10) & 21 & 20 & 5 \\
Ciprofloxacin (5) & $10-12$ & 10 & 10 \\
\hline
\end{tabular}

The table shows clearing zones $(\mathrm{mm})$ observed when eight antibiotics were tested against S. aureus USA300 JE2 in absence (control) and presence of JBC 1847 $(2 \mathrm{mg} / \mathrm{L})$. The change (\%) indicates the difference in clearing zones.

TABLE 4 | Tolerance assay.

\begin{tabular}{lcccc}
\hline Compound & MIC (mg/L) & & MIC (mg/L) & Increase (fold) \\
\cline { 2 - 3 } & Day 1 & & Day 23 & \\
\hline JBC 1847 & 0.5 & 3.5 & 7 \\
Fusidic acid & 0.03 & 7 & 233
\end{tabular}

The table shows minimal inhibitory concentrations (MIC) for JBC 1847 and fusidic acid against Staphylococcus aureus USA300 JE2 at days 1 and 23 during a 23-day test period. Additionally, the increase (fold) in MIC is shown for both compounds.

was carried out in triplicates, as seen in Figure 2. When the concentration of JCB 1847 was $0.5 \times$ MIC, a prolonged phase was observed, and after $24 \mathrm{~h}$, the bacterial concentration reached approximately $10^{3}$ and $0 \mathrm{CFU} / \mathrm{ml}$ in trials 1 and 2, respectively. However, in trial 3, the concentration started to increase after $6 \mathrm{~h}$ and reached the same level as the control curve after $24 \mathrm{~h}$. At the MIC concentration, the bacterial concentration was constantly decreasing, and at trials 1 and 2, the bacterial concentration reached $0 \mathrm{CFU} / \mathrm{ml}$ at $24 \mathrm{~h}$. However, in trial 3, the bacterial count was measured to approximately $10^{3} \mathrm{CFU} / \mathrm{ml}$ after $24 \mathrm{~h}$. At a concentration of $4 \times$ MIC, no viable bacterial cells were measured after $30 \mathrm{~min}$ in all three replicates (Figure 2). 


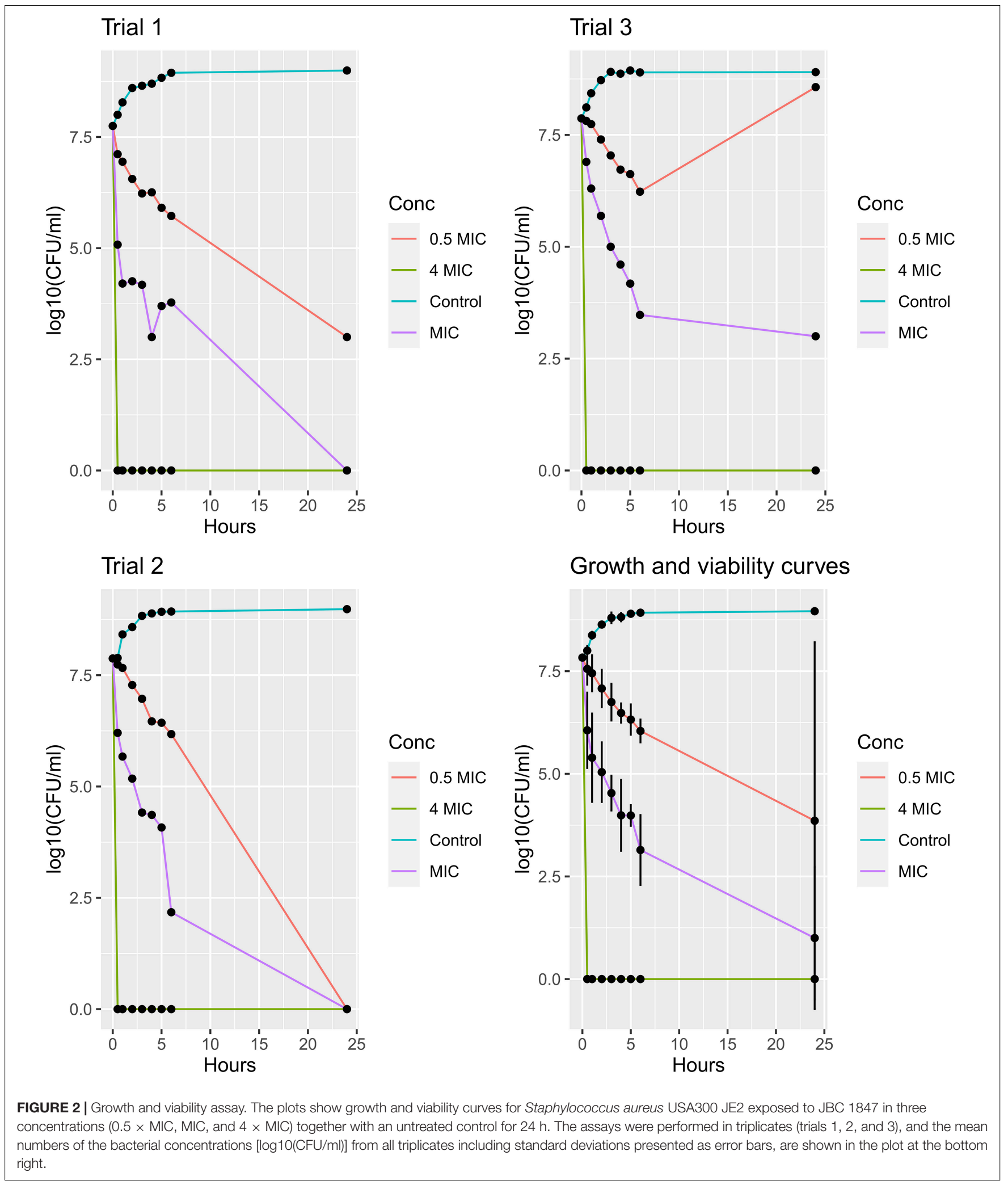

\section{Transmission Electron Microscopy}

To obtain an overview of how JBC 1847 interacts with bacteria, TEM was carried out. Compared with the untreated control, the bacterial cells were clearly lysed and the plasma membrane destroyed, when exposed to JCB 1847 in a concentration corresponding to the MIC (Figure 3). 

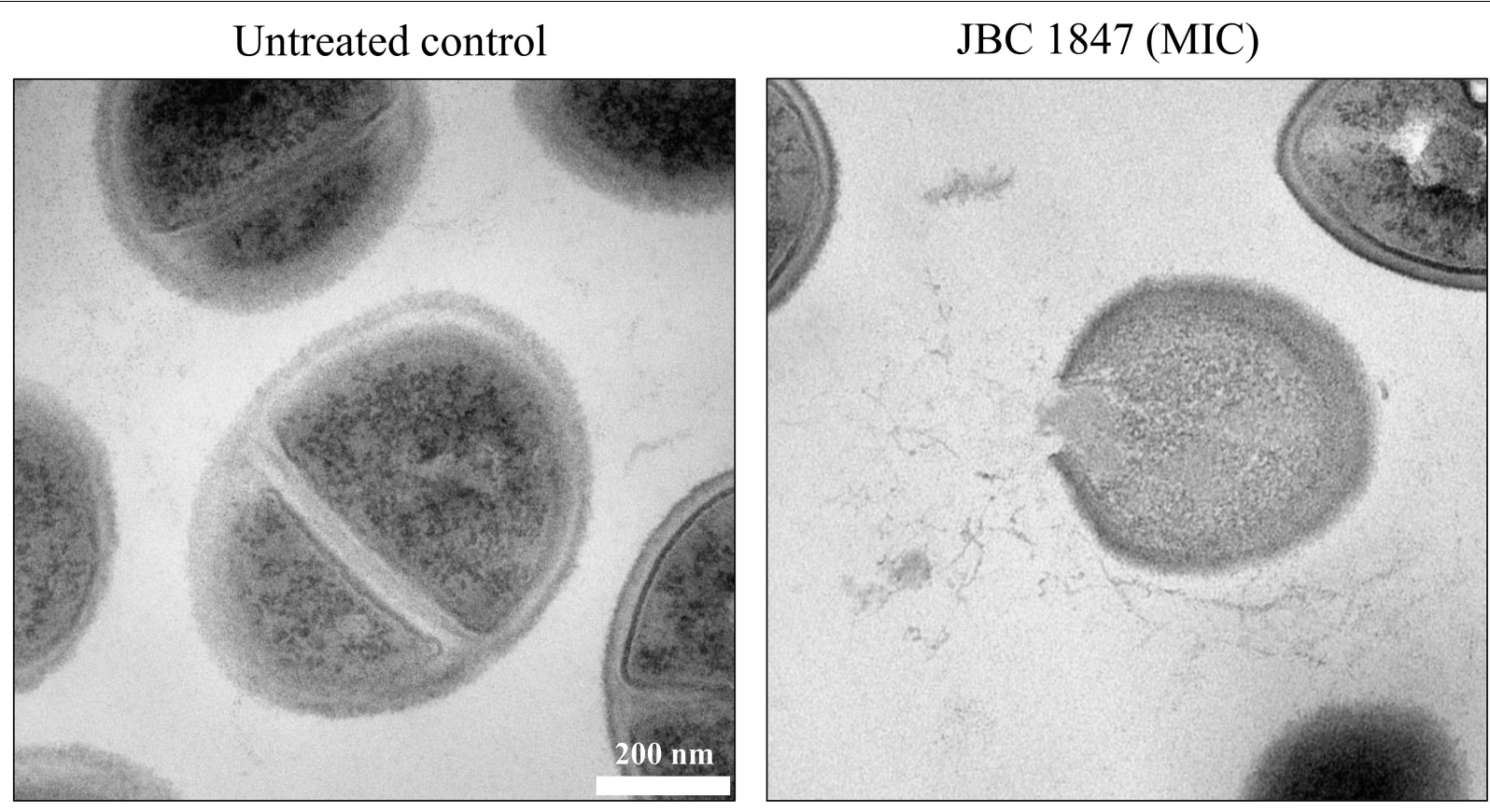

FIGURE 3 | Transmission electron microscopy. The two transmission electron microscopy (TEM) photos show Staphylococcus aureus USA300 JE2 untreated and treated with JBC 1847 in MIC.

\section{Efficacy of JBC 1847 in an in vivo Wound Model}

To study the efficacy of JBC 1847 against MRSA in skin lesions, a murine wound model was performed. The colony count in the inoculum was determined to $8.8 \log 10 \mathrm{CFU} / \mathrm{ml}$, corresponding to $6.8 \log 10 \mathrm{CFU} /$ mouse. During the test period, no mice showed any clinical signs of infection or discomfort in general. The mean number of bacterial concentrations of the vehicle (negative control) was determined to $6.86 \log 10$ CFU. Compared with the vehicle, solutions of 1 and $2 \%$ JBC 1847 reduced the bacterial counts significantly $(P<0.0001)$ with 3.0 and $3.7 \log 10$ CFU, respectively (Figure 4 ). Treatment with $2 \%$ fusidic acid resulted in a $1.5-\log 10-\mathrm{CFU}$ reduction of the bacterial count compared with the vehicle $(P<0.05)$ (Figure 4$)$. Notably, when counting colonies in spots of 10 -fold dilutions of the skin samples, a carry-over effect was observed.

\section{Pharmacological Predictions of JBC 1847 in silico}

To assess the pharmacological properties of JBC 1847 compared with its mother compound promazine, various pharmacodynamic and pharmacokinetic analyses were performed using different Web programs. The results predicted that JBC 1847 will not cross the BBB and possesses a strong affinity for plasma proteins (Table 5). In contrast, promazine was predicted to be able to cross the BBB and had a weak affinity for plasma proteins. Both compounds were found to be less prone to permeate the skin since both had a relatively low $\log K_{\mathrm{p}}$ [the more negative the $\log K_{\mathrm{p}}$, the less skin permeant the molecule (Edwards and Langer, 1994)]. In addition, Table 5 shows that identical tests resulted in different outputs according to which programs were used; e.g., VEGA-QSAR predicted JBC 1847 to be non-mutagenic in the Ames test whereas PreADMET predicted it to be a mutagenic compound. In comparison, promazine was found to be non-mutagenic in both cases. Moreover, JBC 1847 was found to be a non-carcinogen except in the PreADMET rat model, whereas promazine was found to be a carcinogen in all cases. Both JBC 1847 and promazine were identified as cytochrome P450 2D6 (CYP2D6) enzyme inhibitors with a medium risk of being hERG channel inhibitors. Finally, SwissADME predicted a low gastrointestinal (GI) absorption of JBC 1847, whereas PreADMET predicted a middle absorption with Caco- 2 cell lines. Caco- 2 cell lines are used to predict human intestinal absorption (Breemen and Li, 2005).

\section{Ames Test}

The Ames test met all criteria for being a valid test (Supplementary Material), and the genotypes of all strains were confirmed. The mean number of reverse mutated colonies is presented in Table 6. In general, JBC 1847 was found to be a non-mutagenic compound with $\mathrm{MR}$ values of $<2$. However, the MR for S. typhimurium TA1537 was above 2 at a concentration of $4 \mu \mathrm{g} /$ well in the presence and absence of the metabolic activation system S9 (Hubbard et al., 1985; Table 6).

\section{DISCUSSION}

The main purpose of this study was to synthesize a lesstoxic derivative of promethazine that would not cross the BBB but retain its properties as an antimicrobial helper compound 


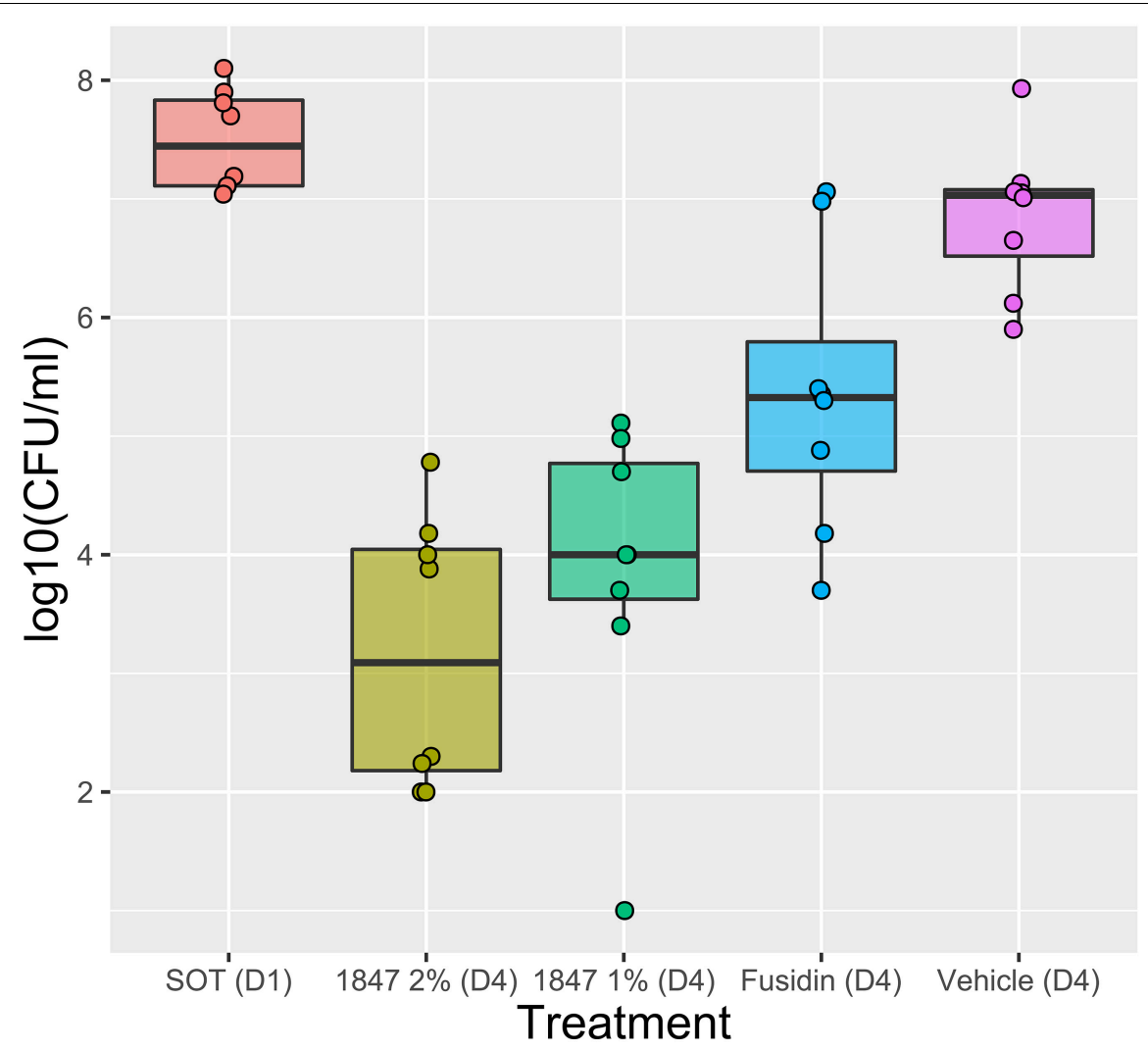

FIGURE 4 | Efficacy of JBC 1847 against Staphylococcus aureus in vivo. The box plot shows bacterial counts [log10(CFU/ml)] from a 4-day wound infection experiment. The sample median is shown within the boxes and the first and third quartile is shown as the upper and lower edge of the boxes, respectively. At day 4 (D4), the bacterial counts were significantly decreased $(P<0.0001)$ when wounds were treated with 1 and $2 \%$ JBC 1847 (1847), compared with the vehicle treatment. Treatment with $2 \%$ Fusidin (fusidic acid) did also result in a significant reduction $(P<0.05)$ in bacterial counts. SOT (D1) is the start of treatment on day 1 (D1).

TABLE 5 | Pharmacological predictions in silico.

\begin{tabular}{|c|c|c|c|}
\hline Program & Test & JBC 1847 & Promazine \\
\hline VEGA-QSAR & Carcinogenicity model (CAESAR) 2.1.9. & Non-carcinogen (OBS reliability) & Carcinogen \\
\hline SwissADME & Log $K_{p}$ (skin permeation) & $-3.05 \mathrm{~cm} / \mathrm{s}$ & $-4.80 \mathrm{~cm} / \mathrm{s}$ \\
\hline SwissADME & Gl absorption & Low & High \\
\hline SwissADME & Blood-brain barrier permeability & No & Yes \\
\hline PreADMET & Ames test & Mutagen & Non-mutagen \\
\hline PreADMET & Carcino_Mouse & Negative & Positive \\
\hline PreADMET & Carcino_Rat & Positive & Positive \\
\hline PreADMET & Caco-2 & 23.0603 & 23.0271 \\
\hline PreADMET & CYP2D6 inhibitor & Yes & No \\
\hline PreADMET & Plasma protein binding & 93.43\% (strong) & $81.82 \%$ (weak) \\
\hline
\end{tabular}

The table shows important pharmacological parameters for JBC 1847 and promazine determined by threes software programs. hERG, human ether-a-go-go-related gene.

(Shibl et al., 1984). This resulted in JBC 1847, and according to in silico analyses, this compound was not permeable to the BBB whereby it will act less toxic to the CNS compared with its mother compound, promazine. JBC 1847 unexpectedly exhibited highly increased antimicrobial activity compared with promazine but seemed to have lost its properties at helper compound. A previous study has determined the MIC for promazine to be $128 \mathrm{mg} / \mathrm{L}$ for both MRSA and E. coli strains using the broth dilution method (Nehme et al., 2018). In contrast, the MIC for JBC 1847 was $0.5 \mathrm{mg} / \mathrm{L}$ when tested against three MRSA strains and $8 / 16 \mathrm{mg} / \mathrm{L}$ 


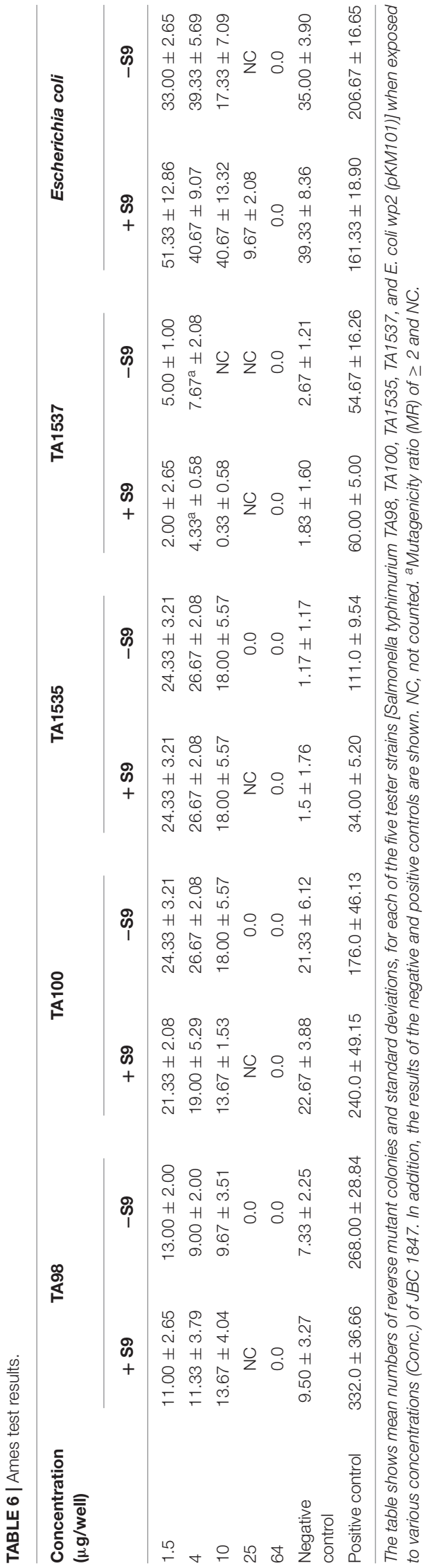

when tested against two E. coli strains (Table 1). Generally, JCB 1847 exhibited most efficient activity against Gram-positive bacteria (MIC range, $0.5-2 \mathrm{mg} / \mathrm{L}$ ) compared with the Gramnegative bacteria (MIC range, $8-32 \mathrm{mg} / \mathrm{L}$ ). In almost all cases the MIC corresponded to the MBC values except for E. faecium ATCC 700221. This indicates that JBC 1847 can be considered a bactericidal compound since MIC and MBC do not vary 4fold from each other (Rhee and Gardiner, 2004). Furthermore, a disc diffusion assay strongly indicated that JBC 1847 had lost its property to act as an antimicrobial adjuvant. No remarkable synergistic or antagonistic effects were observed when tested against two MRSA strains in the presence of eight well-known antibiotics from six different classes (Tables 2, 3). As previously mentioned, several compounds from the phenothiazine group have previously been reported to act as antimicrobial adjuvants (Kristiansen et al., 2003, 2006, 2007, 2010). JCB 1847 was tested for synergistic properties in a $0.5 \times$ MIC concentration $(2 \mathrm{mg} / \mathrm{L})$. Usually, the concentration of phenothiazines have been 5-10fold higher $(10-20 \mathrm{mg} / \mathrm{L})$ than in the present study when tested as a helper compound to oxacillin against MRSA (Kristiansen et al., 2003, 2006). It could be speculated if JBC 1847 could still work efficiently as helper compound if the concentration is raised. To further analyze its antimicrobial properties, a MRSA strain was exposed to JBC 1847 in a growth and viability assay, and generally, concentration-dependent kinetics was observed. The control curves for untreated bacteria and the viability curves for the $4 \times$ MIC concentration turned out as expected and exposure to four MIC resulted in a total decline in the bacterial concentration within $30 \mathrm{~min}$ (Figure 2). At a concentration of $0.5 \times$ MIC, a prolonged lag phase as a result of adaption to an unfavorable growth environment could have been expected (Møller et al., 2016), followed by an exponential growth phase. Only one of the replicates (trial 3) reached an exponential phase, and no real lag phase was observed for any of the triplicates at this concentration. At the MIC, a bactericidal effect was observed for two replicates (trials 1 and 2). This was expected since JBC 1847 had previously exhibited bactericidal properties (Rhee and Gardiner, 2004) in the broth microdilution assay (MIC corresponded to MBC). However, in the third replicate (trial 3), the bacterial concentration did not reach zero within $24 \mathrm{~h}$. It is difficult to conclude precisely on these varying results between the replicates for the MIC. It could be suggested that JBC 1847 was not heated nor vortexed sufficiently to be a homogeneous liquid whereby a decreased concentration was obtained at trial 3 compared with trials 1 and 2. During the assay, contamination could have occurred and hence, blood agar could have been applied when determining the bacterial count to ensure via morphology that the culture had remained uncontaminated during the experiment.

In addition, how easily a MRSA strain would develop resistance to JBC 1847 compared with fusidic acid was investigated in a 23-day period. During this period, the MIC value for fusidic acid was increased 233-fold compared with 7-fold for JBC 1847 (Table 4). This suggests that it is more difficult for S. aureus to develop resistance against JBC 1847 compared with fusidic acid. Previously, fusidic acid-resistant $S$. aureus isolates have been widely reported to constitute an emerging issue in 
clinical settings (O'Neill et al., 2007; Castanheira et al., 2010; Yu et al., 2015) and highly elevated MIC values of $\geq 512 \mu \mathrm{g} / \mathrm{ml}$ have been observed (Castanheira et al., 2010).

When the JBC 1847 activity against three MRSA strains (Table 1) was investigated in the presence of human serum proteins, the ordinary MIC and MBC values were remarkably increased by 128 -fold (from 0.5 to $64 \mathrm{mg} / \mathrm{L}$ ) for all three strains. This strongly indicates that JBC 1847 binds to human serum proteins which corresponded to the in silico analysis that also predicted a strong plasma protein binding ( $\mathrm{PPB}$ ) properties for JCB 1847 (Table 5). This further indicates that JBC 1847 is not suitable for the clinical treatment of sepsis where the free fraction of the antimicrobial compound is required to be high. An elevated degree of PPB will most likely result in a low free fraction of the pharmacologically active compound (Zeitlinger et al., 2011). However, well-known antibiotics such as fusidic acid (PPB, approximately 98\%) (Zeitlinger et al., 2011) and ceftriaxone (PPB, 90-95\%) (Dutta et al., 2001) exhibit a high degree of PPB. Fusidic acid is widely used as a topical agent for the clinical treatment of skin and wound infections caused by $S$. aureus (Kraus and Burnstead, 2011). Considering the efficacy of an antimicrobial agent for dermatological treatment, the degree of PPB is not specifically important. Here, a sufficient skin permeability coefficient $\left(K_{\mathrm{p}}\right)$ value is more essential to ensure a stable concentration of the agent in the treated area instead of spreading it systemically. The skin permeability coefficient for fusidic acid was predicted in silico to $-5.54 \mathrm{~cm} / \mathrm{s}$ using SwissADME (data not shown) which is not far from JBC 1847 which had a coefficient of $-3.05 \mathrm{~cm} / \mathrm{s}$ (Table 5). In addition, the efficacy of the compound was tested against a MRSA strain in an in vivo wound model. JBC 1847 reduced the bacterial concentration in the wounds significantly $(P<0.0001)$ compared with the vehicle treatment and twice as much compared with fusidic acid (Figure 4). Notably, a carry-over effect (Lounis et al., 2008) was observed which indicates that a high concentration of active compound was still present in the skin biopsies at the time of sampling. Therefore, the number of viable bacteria detected on the agar plates during determination of the bacterial counts may have been underestimated. To avoid a carry-over effect, an extra-centrifugation step followed by homogenization and rediluting can be included. Moreover, the experiment lasted for only 4 days, and an extended time period would have provided a more solid data.

To assess the mutagenicity of JBC 1847, Ames test was performed. In general, JBC 1847 has been shown as a nonmutagenic compound with a $\mathrm{MR}$ of $<2$. However, in two cases, when S. typhimurium TA1537 was tested in the absence and presence of a metabolic activation system (S9), the MR was found to be $\geq 2$ (Table 6). This could indicate a slight potential for mutagenicity (Pah and Lakhani, 2012; Wang et al., 2018) which was also predicted in silico (Table 5). In the present study, S9 was derived from rat liver, and notably, previous studies have shown that the outcome of the Ames test may vary according to whether S9 is prepared from rat or human liver extract (Hakura et al., 2005). The S9 system is applied because many xenobiotics are only mutagenic after being metabolized, e.g., by cytochrome P450 enzymes (Hubbard et al., 1985). In fact, many liver and cutaneous enzymes involved in metabolism are the same. However, the frequency of metabolic activity in epidermis is much lower compared with that in the liver. Studies have shown that the phase I metabolic enzyme CYP2D6 is found both in the human liver and skin (Oesch et al., 2007; Zhang et al., 2009). The in silico analyses predicted JBC 1847 to be a CYP2D6 inhibitor (Table 5). Altogether, this means that the pharmacokinetics and pharmacodynamics of JBC 1847 needs to be studied more in-depth including the assessment of a human skin model (Zhang et al., 2009).

\section{CONCLUSION}

The emergence of antimicrobial resistance is an increasing global threat to the public health and therefore, there is an urgent clinical need for novel antimicrobial compounds. Here, we present a novel promazine derivative, JBC 1847, which exhibited a remarkable increased antimicrobial activity. In vitro studies showed efficient microbial activity specifically against Grampositive bacteria and JBC 1847 did also perform well in an MRSA in vivo wound model. In addition, an MRSA strain developed a remarkable low degree of resistance toward JCB 1847 compared with fusidic acid. The activity of JBC 1847 against two MRSA strains was not considerably affected by the presence of eight antibiotics belonging to six different classes, which indicated that the properties of acting as an adjuvant have been lost. In silico predictions showed that JBC 1847 will not pass through the BBB and possess a low skin permeability potential. Both in vitro and in silico studies indicated that the compound possessed strong affinity for plasma proteins. Therefore, we suggest that JBC 1847 holds a promising potential as a novel topical agent for the clinical treatment of $S$. aureus skin infections, but pharmacokinetics and pharmacodynamics must be further studied.

\section{DATA AVAILABILITY STATEMENT}

The original contributions presented in the study are included in the article/Supplementary Material, further inquiries can be directed to the corresponding author/s.

\section{ETHICS STATEMENT}

All animal procedure pertaining to this grant proposal to be carried out at Statens Serum Institut (SSI) are approved under a Danish Animal Experiment Expectorate. The Animal Facility at SSI is responsible for all the Animal Studies performed at SSI. The Animal facility follows the principles of GLP/GMP and has written SOPs for all procedures. The use and housing of the animals comply with the Danish legislation, which is based on the EU Directive 2010/63/EU on the protection of animals used for scientific purposes. The animals are housed in dedicated facilities and handled by experienced technicians. SSI does not have an official IACUC per se, but have an Animal Welfare Committee, which is the equivalent to IACUC. The committee gives guidelines for animal experimentations at SSI an arranges meetings to cover news related to 3 Rs and increase awareness of human use of experimental animals. All major procedures to be 
carried out at SSI as part of this application are already covered by Permissions by the Danish Animal Experiment Expectorate. As a general SSI procedure, The Animal Welfare Committee has decided that each individual experiment further has to be approved by the supervising laboratory animal veterinarians who are also part of the IACUC. This procedure has been put in pace to assure that each single experiment is in line with the permits allowances and to ensure a human use of animals with minimal suffering. These approvals are carried out on rolling basis. If additional procedures are to be included in the studies, this can be requested and amended to the permit on rolling basis. Case management of such an amendment at Danish Animal Experiment Expectorate would take a month of two.

\section{AUTHOR CONTRIBUTIONS}

TR, NJ, IH, SK, ES, SS, and JC: experimental work. TR and NJ: statistics, figures, and tables. TR, NJ, IH, SK, ES, AP, SS, JC, and RO: validation of results. TR, NJ, JC, and RO: wrote the manuscript. TR, AP, and RO: manuscript review. JC and RO: experimental design. All authors contributed to the article and approved the submitted version.

\section{REFERENCES}

Benfenati, E., Manganaro, A., and Gini, G. (2013). VEGA-QSAR: AI inside a platform for predictive toxicology. CEUR Workshop Proc. 1107, 21-28.

Blaskovich, M. A. T., Elliott, A. G., Kavanagh, A. M., Ramu, S., and Cooper, M. A. (2019). In vitro antimicrobial activity of acne drugs against skin-associated bacteria. Sci. Rep. 9, 1-8. doi: 10.1038/s41598-019-50 746-4

Breemen, V. B. R., and Li, Y. (2005). Caco-2 cell permeability assays to measure drug absorption. Expert Opin. Drug Metab. Toxicol. 1, 175-185. doi: 10.1517/ 17425255.1.2.175

Cassini, A., Högberg, L. D., Plachouras, D., Quattrocchi, A., Hoxha, A., Simonsen, G. S., et al. (2019). Attributable deaths and disability-adjusted life-years caused by infections with antibiotic-resistant bacteria in the EU and the European Economic Area in 2015: a population-level modelling analysis. Lancet Infect. Dis. 19, 56-66. doi: 10.1016/S1473-3099(18)30605-4

Castanheira, M., Watters, A. A., Mendes, R. E., Farrell, D. J., and Jones, R. N. (2010). Occurrence and molecular characterization of fusidic acid resistance mechanisms among Staphylococcus spp. from European countries (2008). J. Antimicrob. Chemother. 65, 1353-1358. doi: 10.1093/jac/d kq094

Cheminfo.org (2019). Available online at: http://www.cheminfo.org/Chemistry/ Generate_molfiles/index.html (accessed November 15, 2019).

Coates, A. R., Halls, G., and Hu, Y. (2011). Novel classes of antibiotics or more of the same? Br. J. Pharmacol. 163, 184-194. doi: 10.1111/j.1476-5381.2011.01 250.x

Daina, A., Michielin, O., and Zoete, V. (2017). SwissADME: A free web tool to evaluate pharmacokinetics, drug-likeness and medicinal chemistry friendliness of small molecules. Sci. Rep. 7, 1-13. doi: 10.1038/srep42717

Dutta, P., Mitra, S., Dutta, A., De, A., Chatterjee, M. K., and Bhattacharya, S. K. (2001). Ceftriaxone therapy in ciprofloxacin treatment failure typhoid fever in children. Indian J. Med. Res. 113, 210-213.

Edwards, D. A., and Langer, R. (1994). A linear theory of transdermal transport phenomena. J. Pharm. Sci. 83, 1315-1334. doi: 10.1002/jps.2600830925

Hakura, A., Shimada, H., Nakajima, M., Sui, H., Kitamoto, S., Suzuki, S., et al. (2005). Salmonella/human S9 mutagenicity test: A collaborative study with 58 compounds. Mutagenesis 20, 217-228. doi: 10.1093/mutage/ge i029

\section{FUNDING}

The study was funded by a grant from the Novo Nordisk foundation (grant No. NNF19OC0054692) and a grant from the Innovation Fund Denmark (grant No. 9122-00074B).

\section{ACKNOWLEDGMENTS}

We would like to thank Dr. Med. Bo Söderquist from the Faculty of Medicine and Health, Örebro University, Örebro, Sweden, for providing the C. acnes and S. epidermidis strains. In addition, we would like to thank Senior Scientist Marc Stegger and Head of Contract Research Carina Vingsbo Lundberg from the Department of Bacteria, Parasites and Fungi, Statens Serum Institut, Copenhagen, Denmark, for great guidance.

\section{SUPPLEMENTARY MATERIAL}

The Supplementary Material for this article can be found online at: https://www.frontiersin.org/articles/10.3389/fmicb. 2020.560798/full\#supplementary-material

Hubbard, S. A., Brooks, T. M., Gonzalez, L. P., and Bridges, J. W. (1985). Preparation and characterisation of S9 fractions. Comp. Genet. Toxicol. 16, 413-438. doi: 10.1007/978-1-349-07901-8_50

Kraus, C. N., and Burnstead, B. W. (2011). The safety record of fusidic acid in non-US markets: A focus on skin infections. Clin. Infect. Dis. 52, 527-537. doi: $10.1093 / \mathrm{cid} / \operatorname{cir} 168$

Kristiansen, J. E., Hendricks, O., Delvin, T., Butterworth, T. S., Aagaard, L., Christensen, J. B., et al. (2007). Reversal of resistance in microorganisms by help of non-antibiotics. J. Antimicrob. Chemother. 59, 1271-1279. doi: 10.1093/jac/ $\mathrm{dkm} 071$

Kristiansen, J. E., Thomsen, V. F., Martins, A., Viveiros, M., and Amaral, L. (2010). Non-antibiotics reverse resistance of bacteria to antibiotics. In Vivo 24, 751-754.

Kristiansen, M. M., Leandro, C., Ordway, D., Martins, M., Viveiros, M., Pacheco, T., et al. (2003). Phenothiazines alter resistance of methicillin-resistant strains of Staphylococcus aureus (MRSA) to oxacillin in vitro. Int. J. Antimicrob. Agents 22, 250-253. doi: 10.1016/S0924-8579(03)00200-0

Kristiansen, M. M., Leandro, C., Ordway, D., Martins, M., Viveiros, M., Pacheco, T., et al. (2006). Thioridazine reduces resistance of methicillin-resistant Staphylococcus aureus by inhibiting a reserpine-sensitive efflux pump. In Vivo 20, 361-366. doi: 10.1109/ICIME.2010.5477607

Levy, D. D., Zeiger, E., Escobar, P. A., Hakura, A., van der Leede, B. M., Kato, M., et al. (2019). Recommended criteria for the evaluation of bacterial mutagenicity data (Ames test). Mutat. Res. Genet. Toxicol. Environ. Mutagen. 848:403074. doi: 10.1016/j.mrgentox.2019.07.004

Lounis, N., Gevers, T., Van Den Berg, J., Verhaeghe, T., Van Heeswijk, R., and Andries, K. (2008). Prevention of drug carryover effects in studies assessing antimycobacterial efficacy of TMC207. J. Clin. Microbiol. 46, 2212-2215. doi: 10.1128/JCM.00177-08

Marmulla, R., and Harder, J. (2014). Microbial monoterpene transformations-a review. Front. Microbiol. 5:346. doi: 10.3389/fmicb.2014.00346

Maron, D. M., and Ames, B. N. (1983). Revised methods for the Salmonella mutagenicity test. Mutat. Res. Mutagen. Relat. Subj. 113, 173-215. doi: 10.1016/ 0165-1161(83)90010-9

Møller, T. S. B., Overgaard, M., Nielsen, S. S., Bortolaia, V., Sommer, M. O. A., Guardabassi, L., et al. (2016). Relation betweentetR and tetA expression in tetracycline resistant Escherichia coli. BMC Microbiol. 16:39. doi: 10.1186/ s12866-016-0649-z 
Mortelmans, K., and Zeiger, E. (2000). The Ames Salmonella/microsome mutagenicity assay. Mutat. Res. 455, 29-60. doi: 10.1016/s0027-5107(00) 00064-6

Nehme, H., Saulnier, P., Ramadan, A. A., Cassisa, V., Guillet, C., Eveillard, M., et al. (2018). Antibacterial activity of antipsychotic agents, their association with lipid nanocapsules and its impact on the properties of the nanocarriers and on antibacterial activity. PLoS One 13:e0189950. doi: 10.1371/journal.pone. 0189950

Oesch, F., Fabian, E., Oesch-Bartlomowicz, B., Werner, C., and Landsiedel, R. (2007). Drug-metabolizing enzymes in the skin of man, rat, and pig. Drug Metab. Rev. 39, 659-698. doi: 10.1080/03602530701690366

O’Neill, A. J., Larsen, A. R., Skov, R., Henriksen, A. S., and Chopra, I. (2007). Characterization of the epidemic European fusidic acid-resistant impetigo clone of Staphylococcus aureus. J. Clin. Microbiol. 45, 1505-1510. doi: 10.1128/ JCM.01984-06

Pah, P. M., and Lakhani, A. (2012). Characterization and mutagenicity assessment of characterization and mutagenicity Assessment of PM 2 . 5 and PM 10 PAH at Agra, India. Polycyclic Aromatic Compounds 32, 199-220. doi: 10.1080/ 10406638.2012.657740

PreADMET (2019). Available online at: https://preadmet.bmdrc.kr/ (accessed November15, 2019).

R Core Team (2020). R: A Language and Environment for Statistical Computing. Vienna: R Foundation for Statistical Computing.

Rhee, K. Y., and Gardiner, D. F. (2004). Clinical relevance of bacteriostatic versus bactericidal activity in the treatment of gram-positive bacterial infections. Clin. Inect. Dis. 39, 755-756. doi: 10.1086/422881

Seelig, A., Gottschlich, R., and Devant, R. M. (1994). A method to determine the ability of drugs to diffuse through the blood- brain barrier. Proc. Natl. Acad. Sci. U.S.A. 91, 68-72. doi: 10.1073/pnas.91.1.68

Shibl, A. M., Hammouda, Y., and Al-Sowaygh, I. (1984). Comparative effects of selected phenothiazine tranquilizers and antihistaminics on bacterial cells and possible interactions with antibiotics. J. Pharm. Sci. 73, 841-843. doi: 10.1002/ jps. 2600730638

Singer, A. C., Kirchhelle, C., and Roberts, A. P. (2019). Reinventing the antimicrobial pipeline in response to the global crisis of antimicrobial-resistant infections [version 1; referees: 2 approved]. F1000Research 8, 6-11. doi: 10. 12688/f1000research.18302.1

Snyder, S. H., Banerjee, S. P., Yamamura, H. I, and Greenberg, D. (1974). Drugs, neurotransmitters, and schizophrenia. Science 184, 1243-1253. doi: 10.1126/ science.184.4143.1243

Stenger, M., Behr-Rasmussen, C., Klein, K., Grønnemose, R. B., Andersen, T. E., Klitgaard, J. K., et al. (2017). Systemic thioridazine in combination with dicloxacillin against early aortic graft infections caused by Staphylococcus aureus in a porcine model: In vivo results do not reproduce the in vitro synergistic activity. PLoS One 12:e0173362. doi: 10.1371/journal.pone.0173362
Stenger, M., Hendel, K., Bollen, P., Licht, P. B., Kolmos, H. J., and Klitgaard, J. K. (2015). Assessments of thioridazine as a helper compound to dicloxacillin against methicillin-resistant Staphylococcus aureus: In vivo trials in a mouse peritonitis model. PLoS One 10:e0135571. doi: 10.1371/journal.pone.013 5571

Thorsing, M., Klitgaard, J. K., Atilano, M. L., Skov, M. N., Kolmos, H. J., Filipe, S. R., et al. (2013). Thioridazine induces major changes in global gene expression and cell wall composition in methicillin-resistant Staphylococcus aureus USA300. PLoS One 8:e064518. doi: 10.1371/journal.pone.0064518

Ventola, C. L. (2015). The antibiotic resistance crisis: causes and threats. P T J. 40, 277-283.

Wang, W., Duan, H., Pei, Z., Xu, R., and Qin, Z. (2018). Evaluation by the ames assay of the mutagenicity of UV filters using benzophenone and benzophenone-1. Int. J. Environ. Res. Public Heal. 2018:15. doi: 10.3390/ijerph1 5091907

Wassmann, C. S., Lund, L. C., Thorsing, M., Lauritzen, S. P., Kolmos, H. J., Kallipolitis, B. H., et al. (2018). Molecular mechanisms of thioridazine resistance in Staphylococcus aureus. PLoS One 13:e0201767. doi: 10.1371/journal.pone. 0201767

Yu, F., Liu, Y., Lu, C., Lv, J., Qi, X., Ding, Y., et al. (2015). Dissemination of fusidic acid resistance among Staphylococcus aureus clinical isolates. BMC Microbiol. 15:210. doi: 10.1186/s12866-015-0552-Z

Zarbin, P. H. G., Reckziegel, A., Plass, E., Borges, M., and Francke, W. (2000). Synthesis and biological activity of methyl 2,6,10-trimethyldodecanoate and methyl 2,6,10-trimethyltridecanoate: male-produced sexual pheromones of stink bugs Euschistus heros AND Piezodorus guildinii. J. Chem. Ecol. 26, 2737-2746. doi: 10.1111/j.1399-3011.1983.tb02119.x

Zeitlinger, M. A., Derendorf, H., Mouton, J. W., Cars, O., Craig, W. A., Andes, D., et al. (2011). Protein binding: do we ever learn? Antimicrob. Agents Chemother. 55, 3067-3074. doi: 10.1128/AAC.01433-10

Zhang, Q., Grice, J., Wang, G., and Roberts, M. (2009). Cutaneous metabolism in transdermal drug delivery. Curr. Drug Metab. 10, 227-235. doi: 10.2174/ 138920009787846350

Conflict of Interest: The authors declare that the research was conducted in the absence of any commercial or financial relationships that could be construed as a potential conflict of interest.

Copyright (c) 2020 Ronco, Jørgensen, Holmer, Kromann, Sheikhsamani, Permin, Svenningsen, Christensen and Olsen. This is an open-access article distributed under the terms of the Creative Commons Attribution License (CC BY). The use, distribution or reproduction in other forums is permitted, provided the original author(s) and the copyright owner(s) are credited and that the original publication in this journal is cited, in accordance with accepted academic practice. No use, distribution or reproduction is permitted which does not comply with these terms. 